\title{
NOTA
}

\section{ESTABILIDADE DE AGREGADOS E RESISTÊ NCIA À PENETRAÇÃO EM LATOSSOLOS ADUBADOS POR CINCO ANOS COM BIOSSÓLIDO(1)}

\author{
Zigomar Menezes de Souza(2), Amauri Nelson Beutler(2), \\ Valéria Peruca Melo(3) \& Wanderley J osé de Melo(4)
}

\begin{abstract}
RESUMO
O biossólido tem sido utilizado para fins agrícolas como fonte de nutrientes e condicionante dos atributos físicos do solo. Objetivou-se avaliar o efeito do biossólido na estabilidade de agregados e resistência à penetração de um Latossolo Vermelho distrófico textura média (LVd) e um Latossolo Vermelho eutroférrico argi loso (LVef), em J aboticabal (SP). Utilizaram-se as doses de 0,0, 25,0, 47,5 e 50,0 $\mathrm{Mg} \mathrm{ha}^{-1}$ de massa seca de biossólido que foi incorporado com grade até $0,1 \mathrm{~m}$, antes da semeadura do milho. As amostras foram coletadas no quinto ano, após a colheita do milho, nas camadas de 0,0-0,1; 0,1-0,2; 0,2-0,3 m para determinação da composição granulométrica, matéria orgânica e estabilidade de agregados. A resistência do solo à penetração e umidade do solo foram determi nadas até à profundidade de $0,4 \mathrm{~m}$. O delineamento experimental foi de blocos ao acaso com cinco repetições. $O$ diâmetro médio geométrico dos agregados foi maior na camada de 0,0-0,1 m e a partir da aplicação de $47,5 \mathrm{Mg} \mathrm{ha}^{-1}$ de biossólido nos dois solos. A aplicação de biossólido não influiu na resistência do solo à penetração, tampouco na umidade nos dois solos.
\end{abstract}

Termos de indexação: atributos físi cos, matéria orgânica, lodo de esgoto.

(1) Recebido para publicação em março de 2003 e aprovado em novembro de 2004.

(2) Doutorando do Departamento de Solos e Adubos, Faculdade de Ciências Agrárias e Veterinárias - UNESP. Via de acesso Prof. Paulo Donato Castellane s/n, CEP $14870000 \mathrm{~J}$ aboticabal (SP). Bolsista da FAPESP. E-mail: amaurib@yahoo.com.br

(3) Doutoranda do Departamento de Tecnologia, FCAV/UNESP. Bolsista da FAPESP. E-mail: vpmelo@bol.com.br

(4) Professor Titular de Bioquímica do Departamento de Tecnologia, UNESP. E-mail: wjmelo@fcav.unesp.br 


\title{
SUMMARY: AGGREGATE STABILITY AND RESISTANCE TO PENETRATION IN OXISOLS FERTILIZED FOR FIVE YEARS WITH BIOSSOLID
}

\begin{abstract}
Biossol id has been used in agriculture as nutrient sourceand to improve soil physical attributes. The effect of biossolid on the aggregatestability and soil penetration resi stance of a medium textureOxisol (LVd) and dayey Oxisol (LVe) in J aboticabal (SP) wereevaluated. Dry biosolid mass was applied with a harrow at rates of $0.0,25.0,47.5,50.0 \mathrm{Mg} \mathrm{ha}^{-1}$, incorporated at $0.1 \mathrm{~m}$ depth before sowing the maize. Samples were collected in the fifth year after the maize harvest from the 0.0-0.1, 0.1-0.2, 0.2-0.3 $\mathrm{m}$ layers to determinate the texture, organic matter and aggregate stability. The soil penetration resistance and soil moisture were determined down to a depth of $0.4 \mathrm{~m}$. The complete random block design was used in fivereplications. The mean geometric aggregate diameter was greatest in the 0.0-0.1 m layer and at bi osolid applications above $47.5 \mathrm{Mg} \mathrm{ha}^{-1}$ in both soils. Theapplication of $50.0 \mathrm{Mg} \mathrm{ha}^{-1}$ biosolid did not significantly modify the soil resi stanceto penetration or the soil moisturein both soils.
\end{abstract}

Index terms: physical attributes, organic matter, sewage sludge, biossolid.

\section{INTRODUÇÃO}

O lodo de esgoto é um subproduto das Estações de Tratamento de Esgoto (ETE) de cidades e indústrias, o qual, após devidamentetratado e seco, é denominado biossólido (Melo et al., 2001). Este é um resíduo de grandes utilidades para fins agrícol as, quer como condicionante das propriedades físicas, químicas e biológicas do solo, em virtude de seu conteúdo de material orgânico, quer como fonte de nutrientes para as plantas cultivadas, em virtude de sua composição química (M elo et al., 1994).

Em solos tropicais, onde a matéria orgânica desempenha papel de fundamental importância, a utilização de biossólido torna-se uma alternativa viável para a elevação dos teores de matéria orgânica. Entretanto, dada a presença de metais pesados neste material, deve-se evitar a utilização de doses excessivas, as quais são cal culadas deacordo com teor inicial de metais pesados no solo; quantidade total adicionada de metais pesados; carga total cumulativa deelementos metálicos; toxidez desses el ementos para as plantas; val ores limites de concentração de metais pesados nos solos; interação entre os elementos e características dos solos; e sensibilidade da planta (Kabata-Pendias \& Pendias, 1992).

Na literatura, encontram-se vários trabal hos que evidenciam o efeito benéfico da matéria orgânica na estabilidade deagregados (Wei et al., 1985; J orge et al., 1991; Hadas et al. 1994; Campos et al., 1995; Albiach, 1997; Martinez-Mena et al., 1998; Beutler et al., 2001; Grandy et al., 2002; Whalen \& Chang, 2002) e na resistência do solo à penetração (Kumar et al., 1985; Smith et al., 1997). A aplicação de biossólido, além de aumentar o teor de matéria orgânica, pode aumentar a agregação e alterar a proporção de agregados estáveis em água (J orge et al., 1991). Epstein (1975) verificou maior estabilidade deagregados em sol o querecebeu adição de lodo de esgoto, enquanto J orge et al. (1991), estudando a adição de lodo de esgoto em Latossolo Vermelho, verificaram aumento da agregação do solo em relaçãoà testemunha. Aggelides \& Londra (2000) observaram redução da resistência à penetração com aplicação de lodo de esgoto e lixo urbano.

A grande produção de biossólido nos centros urbanos levou pesquisadores a intensificarem os estudos para utilização desses resíduos para fins agrícolas. Entretanto, poucos estudos têm sido realizados recentemente sobre a influência do biossólido nos atributos físicos do solo, principal mente sobre a resistência do solo à penetração (Aggelides \& Londra, 2000).

Este estudo teve o objetivo de avaliar o efeito da aplicação de biossólido durante cinco anos na estabilidade de agregados e na resistência à penetração de dois Latossol os cultivados com milho.

\section{MATERIAL E MÉTODOS}

O estudo foi real izado em um Latossolo Vermelho distrófico típico textura média $A$ moderado caulinítico ( $(\mathrm{V} V \mathrm{~d})$ e em um Latossolo Vermelho eutroférrico típico textura argilosa $A$ moderado caulinítico-oxídico (L Vef) (Quadro 1), localizados na fazenda de ensino e pesquisa da FCAV/UNESP de J aboticabal (SP). A área do experimento está localizada entre as coordenadas $21^{\circ} 04^{\prime}$ e $21^{\circ} 21^{\prime}$ delatitude Sul e $48^{\circ} 08^{\prime}$ e $48^{\circ} 26^{\prime}$ ' delongitudeOeste. O clima éo mesotérmico de inverno seco (Cwa) pelo critério de classificação climática de Köppen. 
Utilizaram-se as seguintes doses de massa seca de biossólido (Quadro 2), obtidos na Estação de Tratamento de Esgoto da cidade de Barueri (SP), administrada pela SABESP: 0,$0 ; 25,0 ; 47,5$ e $50,0 \mathrm{Mg} \mathrm{ha}^{-1}$ aplicadas manual mente na superfície eincorporadas até 0,1 m de profundidade com grade, antes da semeadura do mil ho. Notratamento de 25,0 e 50,0 $\mathrm{Mg} \mathrm{ha}^{-1}$, foram aplicados 5,0 e10,0 $\mathrm{Mg} \mathrm{ha}^{-1} \mathrm{ano}^{-1}$ debiossólidoe, notratamento de 47,5 $\mathrm{Mg} \mathrm{ha}^{-1}$, foram aplicados 2,5 $\mathrm{Mg} \mathrm{ha}^{-1}$, durante três anos, e 20,0 $\mathrm{Mg} \mathrm{ha}^{-1}$, nos dois últimos anos. O milho foi semeado anualmente no espaçamento de 0,9 m e adubado de acordo com as recomendações técnicas para a cultura.

As amostras de sol o foram col etadas em abril de 2002 , no quinto ano do experimento, após a col heita do milho, nas camadas de $0,0-0,1 ; 0,1-0,2$ e $0,2-$ $0,3 \mathrm{~m}$. As amostras deformadas foram passadas em peneira de $2 \mathrm{~mm}$ para determinação da composição granulométrica por meio da dispersão com água e $\mathrm{NaOH}$ 0,1 mol L-1 eagitação lenta (16 h), tendo sido a argila obtida pelo método da pipeta, segundo Embrapa (1997). O C orgânico foi obtido por oxidação (E mbrapa, 1997) ea MO, multiplicando-se o C orgânico pelo fator 1,724 . As amostras indeformadas foram secas ao ar e passadas na peneira de 7,93 $\mathrm{mm}$ para determinação da estabilidade de agregados após pré-umedecimento com álcool, segundo método da E mbrapa (1997), utilizando as peneiras com abertura de malha de 4,76; 2,00; 1,00; 0,50; 0,25; 0,125 mm eagitaçãolenta por $15 \mathrm{~min}$.
A resistência dosolo ò penetração foi determinada nas camadas de $0,0-0,1 ; 0,1-0,2 ; 0,2-0,3$ e0,3-0,4 m, na entrelinha da cultura, com o penetrômetro de impacto (model olAA/Planal sucar- Stolf) (Stolf et al., 1983), com ângulo de cone de $30^{\circ}$, sendo os cál cul os real izados, segundo Stolf (1991). A umidade do solo foi determinada, nas mesmas camadas, em amostras retiradas com trado holandês, as quais foram secas em estufa a $\pm 105^{\circ} \mathrm{C}$ durante $24 \mathrm{~h}$, segundo método da Embrapa (1997).

Utilizou-se o delineamento experimental em blocos casualizados, em esquema fatorial, com quatro doses de biossólido e cinco repetições, tendo cada parcela a dimensão de $54 \mathrm{~m}^{2}$. Realizou-se a análise de variância, e, quando significativa, aplicou-se o teste de Tukey a $5 \%$, para comparação das médias.

\section{RESULTADOS E DISCUSSÃO}

A composição química do biossólido varia de acordo com o local de origem, ou seja, se de uma área tipicamente residencial ou tipicamente industrial, tendo como principais vantagens os elevados teores de MO (40-60\%), macro e micronutrientes, os quais exercem papel fundamental na produção agrícola (Melo et al., 2001). O biossólido utilizado no experimento apresentou teores de metais pesados dentro dos valores permitidos pela legislação, inclusive $\mathrm{Cd}, \mathrm{Pb}$ e $\mathrm{Ni}$.

\section{Quadro 1. Caracterização granulométrica em di ferentes camadas no Latossolo Vermelho distrófico típico e Latossolo Vermelho eutroférrico típico}

\begin{tabular}{|c|c|c|c|c|c|c|}
\hline \multirow{2}{*}{ Atributo físico } & \multicolumn{6}{|c|}{ Camada (m) } \\
\hline & $0,0-0,1$ & $0,1-0,2$ & $0,2-0,3$ & $0,0-0,1$ & $0,1-0,2$ & $0,2-0,3$ \\
\hline & \multicolumn{6}{|c|}{$\mathrm{g} \mathrm{kg}^{-1}$} \\
\hline & \multicolumn{3}{|c|}{ Latossolo Vermelho distrófico típico } & \multicolumn{3}{|c|}{ Latossolo Vermel ho eutroférrico típico } \\
\hline Areia grossa & 389 & 349 & 356 & 90 & 86 & 77 \\
\hline Areia fina & 298 & 311 & 296 & 128 & 125 & 125 \\
\hline Silte & 68 & 62 & 63 & 297 & 281 & 273 \\
\hline Argila & 245 & 278 & 285 & 485 & 508 & 525 \\
\hline
\end{tabular}

Quadro 2. Caracterização química do biossólido da Estação de Tratamento de Esgoto de Barueri (SP)

\begin{tabular}{|c|c|c|c|c|c|c|c|c|}
\hline \multicolumn{5}{|c|}{ Macronutriente } & \multicolumn{4}{|c|}{ Micronutriente } \\
\hline $\mathbf{N}$ & $\mathbf{P}$ & $\mathbf{K}$ & $\mathrm{Ca}$ & Mg & Mn & $\mathbf{F e}$ & Zn & $\mathbf{P b}$ \\
\hline \multicolumn{5}{|c|}{$\mathrm{g} \mathrm{kg}^{-1}$} & \multicolumn{4}{|c|}{$\mathrm{mg} \mathrm{kg}^{-1}$} \\
\hline 36,54 & 17,15 & 1,62 & 26,95 & 3,68 & 248 & 20.294 & 2.717 & 219 \\
\hline
\end{tabular}


A adição de biossólido proporcionou incrementos significativos nos conteúdos de MO na camada de 0,0 a 0,1 m no LVd e LVef (Quadro 3), condizente com a incorporaçãonesta profundidade, confirmando os estudos de Wei et al . (1985) eAl biach et al. (2001). Neste sentido, M elo (2002) não verificou diferenças significativas após três anos de aplicação das mesmas doses de biossólido. Nas camadas de 0,1 a $0,3 \mathrm{~m}$, não houve diferença nos teores de $\mathrm{MO}$ entre tratamentos e profundidades.

O maior teor de MO com aplicação de biossólido na camada de 0,0-0,1 m resultou em maior estabilidade de agregados nos dois solos, verificados pel o diâmetro médi o geométrico (DMG) e agregados $>2 \mathrm{~mm}$ (Quadro 4), concordando com os estudos de Wei et al. (1985), os quais verificaram que a utilização de lodo de esgoto aumentou o teor de MO, a estabilidade de agr egados e o índice de agregação. A maior agregação atribuída ao aumento no teor de MO deve-se ao fato de ela apresentar grande superfícieespecífica ecapacidade de troca de cátions, possibilitando maior número de ligações el etrostáticas entre esta eas partículas de sol o. Além disso, a sua decomposição por microrganismos resulta na formação de inúmeros compostos importantes na cimentação e estabilização dos agregados (Angers, 1992). Esse efeito pronunciado da MO na agregação é demonstrado, ao verificar-se maior estabilidade de agregados, quando da aplicação anual do biossólido em superfície e incorporação na camada de 0,0-0,1 m, uma vez que o revolvimento causado com a grade tem o efeito de fragmentar os agregados do solo.

O DMG foi superior na camada de 0,0-0,1 m nos dois solos, a partir da dose de 47,5 $\mathrm{Mg} \mathrm{ha}^{-1}$, de biossólido, sendo inferior ao obtido na dose de 50,0 $\mathrm{Mg} \mathrm{ha}^{-1}$ (Quadro 4). Na dose de 25,0 Mg ha-1, não houve diferença significativa, quando comparado com a testemunha. J orge et al. (1991), utilizando $10,0 \mathrm{Mg} \mathrm{ha}^{-1} \mathrm{ano}^{-1}$ de lodo de esgoto com e sem cal cário em Latossolo Vermelho-E scuro argiloso cultivado com milho, verificaram o aumento do índice de agregação após quatro anos. Neste contexto, Albiach (1997) verificou maior estabilidade de agregados com a aplicação de $24,0 \mathrm{Mg} \mathrm{ha}^{-1} \mathrm{ano}^{-1}$ de lodo de esgoto durante cinco anos, enquanto, Logan \& Harrison (1995) verificaram maior agregação após um ano de aplicação de lodo de esgoto. O maior DMG na dosede $50,0 \mathrm{Mg} \mathrm{ha}^{-1}$ deveuse possivel mente à adição gradual de $10,0 \mathrm{Mg} \mathrm{ha}^{-1}$ ano-1 de biossól ido, comparado à dose de $47,5 \mathrm{Mg} \mathrm{ha}^{-1}$ querecebeu altas doses apenas nos dois últimos anos de cultivo.

O aumento da agregação, inclusive no L Vef, com a aplicação de biossólido é destacável, uma vez que o LVef apresentou maior estabilidade natural de agregados decorrente do maior teor de $\mathrm{MO}$ e, ainda, segundo Ferreira et al. (1999), dos óxidos de Fee Al que conferem a formação de uma microestrutura estável a esse solo. Assim, segundo J orge et al. (1991), é previsível queapenas uma grande variação nos fatores de formação dos agregados, em especial o incremento nos teores de $\mathrm{MO}$, poderia ter um efeito apreciável na estabilidade de agregados. Maior agregação com a aplicação de lodo de esgoto em Latossolos oxídicos também foi observada por Epstein (1975) e J orge et al. (1991).

Nos dois solos, observou-se maior agregação na camada de 0,0-0,1 $\mathrm{m}$ em relação à de 0,1-0,2 $\mathrm{m}$ e $0,2-0,3 \mathrm{~m}$, tendo sido verificado no LVef maior DMG com a aplicação de biossólido nas camadas de 0,10,2 e 0,2-0,3 m. I sto não foi observado no $L V d$, possivelmente em razão do alto coeficiente de variação dos resultados $(28,72 \%$ ) em relação ao L Vef $(7,99 \%)$, fato que não permitiu obter diferenças estatísticas entre as camadas no LVd. Além disso, segundo Mel o et al. (2004), o LVef apresentou maior porosidade comparado ao LVd, o que, segundo Ferreira et al. (1999), facilitou a percolação de água e lixiviação de íons em profundidade, os quais atuavam na agregação do solo, aumentando, assim, a agregação em camadas mais profundas.

Quadro 3. Conteúdo de matéria orgânica no solo para diferentes doses de biossólido e camadas no Latossolo Vermelho distrófico típico e Latossolo Vermelho eutroférrico típico

\begin{tabular}{|c|c|c|c|c|c|c|}
\hline \multirow{2}{*}{ Dose de biossólido } & \multicolumn{6}{|c|}{ Camada (m) } \\
\hline & $0,0-0,1$ & $0,1-0,2$ & $0,2-0,3$ & $0,0-0,1$ & $0,1-0,2$ & $0,2-0,3$ \\
\hline \multirow[t]{2}{*}{$\mathrm{Mg} \mathrm{ha}^{-1}$} & - & - & - & - & - & - \\
\hline & \multicolumn{3}{|c|}{ Latossolo Vermelho distrófico típico } & \multicolumn{3}{|c|}{ Latossolo Vermel ho eutroférrico típico } \\
\hline $\begin{array}{r}0,0 \\
25,0 \\
47,5 \\
50,0\end{array}$ & $\begin{array}{l}16,60 \mathrm{Ca} \\
20,40 \mathrm{Ba} \\
27,00 \mathrm{Aa} \\
26,40 \mathrm{Aa}\end{array}$ & $\begin{array}{l}13,40 \mathrm{Ab} \\
13,20 \mathrm{Ab} \\
12,80 \mathrm{Ab} \\
13,20 \mathrm{Ab}\end{array}$ & $\begin{array}{l}11,20 \mathrm{Ab} \\
11,00 \mathrm{Ab} \\
10,80 \mathrm{Ab} \\
11,40 \mathrm{Ab}\end{array}$ & $\begin{array}{l}28,40 \mathrm{Ca} \\
31,00 \mathrm{Ba} \\
38,00 \mathrm{Aa} \\
36,60 \mathrm{Aa}\end{array}$ & $\begin{array}{l}21,00 \mathrm{Ab} \\
22,00 \mathrm{Ab} \\
21,20 \mathrm{Ab} \\
22,40 \mathrm{Ab}\end{array}$ & $\begin{array}{l}18,80 \mathrm{Ab} \\
20,40 \mathrm{Ab} \\
19,00 \mathrm{Ab} \\
20,40 \mathrm{Ab}\end{array}$ \\
\hline C.V. (\%) & \multicolumn{3}{|c|}{9,38} & \multicolumn{3}{|c|}{8,28} \\
\hline
\end{tabular}

Médias seguidas da mesma letra maiúscula, na coluna, e minúscula, na linha, para a mesma variável e solo, não diferem pelo teste de Tukey a $5 \%$. 
Quadro 4. Diâmetro médio geométrico (DMG), agregados maiores que $2 \mathbf{~ m m}$ e menores que $1 \mathrm{~mm}$ para diferentes doses de biossólido e camadas no Latossolo Vermel ho distrófico típico e Latossolo Vermelho eutroférrico típico

\begin{tabular}{|c|c|c|c|c|c|c|}
\hline \multirow{2}{*}{ Dose de biossólido } & \multicolumn{6}{|c|}{ Camada (m) } \\
\hline & $0,0-0,1$ & $0,1-0,2$ & $0,2-0,3$ & $0,0-0,1$ & $0,1-0,2$ & $0,2-0,3$ \\
\hline \multirow[t]{2}{*}{$\mathrm{Mg} \mathrm{ha}^{-1}$} & \multicolumn{3}{|c|}{ Latossolo Vermel ho distrófico típico } & \multicolumn{3}{|c|}{ L atossolo Vermel ho eutroférrico típico } \\
\hline & \multicolumn{6}{|c|}{ Diâmetro médio geométrico, mm } \\
\hline $\begin{array}{r}0,0 \\
25,0 \\
47,5 \\
50,0\end{array}$ & $\begin{array}{l}1,16 \mathrm{Ca} \\
1,38 \mathrm{Ca} \\
2,02 \mathrm{Ba} \\
2,59 \mathrm{Aa}\end{array}$ & $\begin{array}{l}0,42 A b \\
0,44 A b \\
0,55 A b \\
0,60 A b\end{array}$ & $\begin{array}{l}0,42 \mathrm{Ab} \\
0,48 \mathrm{Ab} \\
0,49 \mathrm{Ab} \\
0,55 \mathrm{Ab}\end{array}$ & $\begin{array}{l}2,12 \mathrm{Ca} \\
2,21 \mathrm{BCa} \\
2,41 \mathrm{Ba} \\
3,29 \mathrm{Aa}\end{array}$ & $\begin{array}{l}0,84 \mathrm{Bb} \\
0,86 \mathrm{Bb} \\
1,19 \mathrm{Ab} \\
1,24 \mathrm{Ab}\end{array}$ & $\begin{array}{l}0,70 \mathrm{Bb} \\
0,89 \mathrm{Ab} \\
0,97 \mathrm{Ab} \\
1,09 \mathrm{Ab}\end{array}$ \\
\hline \multirow[t]{2}{*}{ C.V. (\%) } & & 28,72 & & & 7,99 & \\
\hline & \multicolumn{6}{|c|}{ Agregados $>2 \mathrm{~mm}, \%$} \\
\hline $\begin{array}{r}0,0 \\
25,0 \\
47,5 \\
50,0\end{array}$ & $\begin{array}{l}40,75 \mathrm{Ca} \\
50,71 \mathrm{BCa} \\
65,88 \mathrm{ABa} \\
73,64 \mathrm{Aa}\end{array}$ & $\begin{array}{r}6,77 \mathrm{Ab} \\
8,84 \mathrm{Ab} \\
11,28 \mathrm{Ab} \\
14,78 \mathrm{Ab}\end{array}$ & $\begin{array}{r}7,10 \mathrm{Ab} \\
8,68 \mathrm{Ab} \\
9,91 \mathrm{Ab} \\
10,68 \mathrm{Ab}\end{array}$ & $\begin{array}{l}62,00 \mathrm{Ba} \\
64,42 \mathrm{Ba} \\
55,79 \mathrm{Ba} \\
80,79 \mathrm{Aa}\end{array}$ & $\begin{array}{l}28,85 \mathrm{Ab} \\
25,91 \mathrm{Ab} \\
32,69 \mathrm{Ab} \\
35,13 \mathrm{Ab}\end{array}$ & $\begin{array}{l}15,30 \mathrm{Cb} \\
23,95 \mathrm{BCb} \\
27,85 \mathrm{ABb} \\
31,85 \mathrm{Ab}\end{array}$ \\
\hline \multirow[t]{2}{*}{ C.V. (\%) } & & 28,51 & & & 10,49 & \\
\hline & \multicolumn{6}{|c|}{ Agregados $<1 \mathrm{~mm}, \%$} \\
\hline $\begin{array}{r}0,0 \\
25,0 \\
47,5 \\
50,0\end{array}$ & $\begin{array}{l}49,03 \mathrm{Ab} \\
39,01 \mathrm{Ab} \\
28,89 \mathrm{Bb} \\
20,62 \mathrm{Bb}\end{array}$ & $\begin{array}{l}80,31 \mathrm{Aa} \\
75,04 \mathrm{Aa} \\
71,41 \mathrm{Aa} \\
70,23 \mathrm{Aa}\end{array}$ & $\begin{array}{l}81,17 \mathrm{Aa} \\
78,07 \mathrm{Aa} \\
76,26 \mathrm{Aa} \\
73,41 \mathrm{Aa}\end{array}$ & $\begin{array}{l}25,85 \mathrm{Ab} \\
23,47 \mathrm{Ab} \\
21,70 \mathrm{Ac} \\
12,29 \mathrm{Bc}\end{array}$ & $\begin{array}{l}54,45 \mathrm{Aa} \\
51,97 \mathrm{Aa} \\
44,74 \mathrm{Bb} \\
42,18 \mathrm{Bb}\end{array}$ & $\begin{array}{l}61,09 \mathrm{Aa} \\
54,97 \mathrm{Ba} \\
52,35 \mathrm{Ba} \\
48,81 \mathrm{Ba}\end{array}$ \\
\hline C.V. (\%) & & 12,42 & & & 6,74 & \\
\hline
\end{tabular}

Médias seguidas da mesma letra maiúscula, na coluna, e minúscula, na linha, para a mesma variável e solo, não diferem pelo teste de Tukey a $5 \%$.

$\mathrm{Na}$ classe de agregados maiores que $2 \mathrm{~mm}$, foram encontrados val ores superiores na camada de 0,0$0,1 \mathrm{~m}$ a partir da dose de 47,5 e 50,0 $\mathrm{Mgha}^{-1}$ de biossólido, no LVd e LVef, respectivamente, confirmando os estudos de J orge et al. (1991), que verificaram valores superiores de agregados $>2 \mathrm{~mm}$ com aplicação de 10,0 $\mathrm{Mg} \mathrm{ha}^{-1}$ de lodo de esgoto durante quatro anos em Latossolo Vermelho argiloso. Na camada de 0,1-0,3 m, não houve incremento significativo na classe de agregados $>2 \mathrm{~mm}$ com a aplicação de biossólido, com exceção da camada de 0,2-0,3 m no LVef.

Observaram-se, para a classe de agregados $<1 \mathrm{~mm}$, valores inferiores na camada de 0,0-0,1 m do LVd e, a partir da dose de 47,5 e 50,0 $\mathrm{Mg} \mathrm{ha}^{-1}$ de biossólido no LVef, confirmando os estudos de J orge et al. (1991). No LVef, ocorreu efeito benéfico do bi ossóli ido na agregação, com menor percentagem de agregados na classe $<1 \mathrm{~mm}$ a partir de $47,5 \mathrm{Mg} \mathrm{ha}^{-1}$, não verificado no LVd.

Para a resistência do solo à penetração e umidade do solo, a análise de variância não mostrou interação entre as doses de biossólido e a profundidade nos dois solos. A aplicação de até $50,0 \mathrm{Mg} \mathrm{ha}^{-1}$ de biossólido não alterou significativamente a resistência do solo à penetração e a umidade nos dois solos (Quadro 5). J á Aggel ides \& Londra (2000) verificaram menor resistência do solo à penetração a partir da aplicação de $78,0 \mathrm{Mg} \mathrm{ha}^{-1} \mathrm{ano}^{-1}$ de uma mistura de $62 \%$ de lixo doméstico, $21 \%$ de lodo de esgoto e $17 \%$ de serragem a $0,15 \mathrm{~m}$ de profundidade em um solo argiloso. Neste sentido, Smith et al. (1997) não observaram diferença nos valores de resistência à penetração, quando os solos apresentavam mais de $300 \mathrm{~g} \mathrm{~kg}^{-1}$ de argila de acordo com a variação de 1,6 a $57,7 \mathrm{~g} \mathrm{~kg}^{-1}$ do teor de MO, sendo verificada a influência desta em solos arenosos.

O menor valor de resistência do sol o à penetração foi observado na camada de $0,0-0,1 \mathrm{~m}$, graças ao revolvimento anual do solo nesta profundidade, 0 qual proporciona uma descompactação dessa camada (Quadro 5). A MO não teve efeito, uma vez que teve a amplitude das variações semel hante entre os tratamentos e não alterou significativamente os valores de resistência à penetração.

Verificou-se incremento da umi dadee resistência do sol o à penetração (Quadro 5), bem como redução doteor de MO com a profundidade(Quadro 3). Este resultado confirma os estudos de Beutler et al. 
Quadro 5. Resistência do solo à penetração e umidade gravimétrica em diferentes doses de biossólido e camadas no Latossolo Vermelho distrófico típico e Latossolo Vermelho eutroférrico típico

\begin{tabular}{|c|c|c|c|c|c|c|c|c|}
\hline \multirow{2}{*}{$\begin{array}{c}\text { Dose de } \\
\text { biossólido }\end{array}$} & \multicolumn{8}{|c|}{ Camada (m) } \\
\hline & $0,0-0,1$ & $0,1-0,2$ & $0,2-0,3$ & $0,3-0,4$ & $0,0-0,1$ & $0,1-0,2$ & $0,2-0,3$ & $0,3-0,4$ \\
\hline \multirow[t]{2}{*}{ Mg ha-1 } & \multicolumn{4}{|c|}{ Latossolo Vermel ho distrófico típico } & \multicolumn{4}{|c|}{ Latossolo Vermel ho eutroférrico típico } \\
\hline & \multicolumn{8}{|c|}{ Resistência do solo à penetração, MPa } \\
\hline $\begin{array}{r}0,0 \\
25,0 \\
47,5 \\
50,0\end{array}$ & $\begin{array}{l}1,58 \mathrm{AC} \\
1,48 \mathrm{AC} \\
1,59 \mathrm{AC} \\
1,22 \mathrm{AC}\end{array}$ & $\begin{array}{l}2,58 \mathrm{Aa} \\
2,46 \mathrm{Aa} \\
2,42 \mathrm{Aa} \\
2,32 \mathrm{Aa}\end{array}$ & $\begin{array}{l}\text { 2,39 Aab } \\
\text { 2,29 Aab } \\
2,20 \mathrm{Aab} \\
2,20 \mathrm{Aab}\end{array}$ & $\begin{array}{l}2,39 \mathrm{Ab} \\
2,10 \mathrm{Ab} \\
1,78 \mathrm{Ab} \\
1,97 \mathrm{Ab}\end{array}$ & $\begin{array}{l}1,68 \mathrm{Ab} \\
1,96 \mathrm{Ab} \\
1,50 \mathrm{Ab} \\
1,28 \mathrm{Ab}\end{array}$ & $\begin{array}{l}2,57 \mathrm{Aa} \\
3,30 \mathrm{Aa} \\
2,57 \mathrm{Aa} \\
2,83 \mathrm{Aa}\end{array}$ & $\begin{array}{l}2,76 \mathrm{Aa} \\
3,68 \mathrm{Aa} \\
2,63 \mathrm{Aa} \\
3,39 \mathrm{Aa}\end{array}$ & $\begin{array}{l}2,87 \mathrm{Aa} \\
3,64 \mathrm{Aa} \\
2,73 \mathrm{Aa} \\
3,19 \mathrm{Aa}\end{array}$ \\
\hline 50,0 & \multicolumn{8}{|c|}{ U midade gravimétrica, dag kg-1 } \\
\hline $\begin{array}{r}0,0 \\
25,0 \\
47,5 \\
50,0\end{array}$ & $\begin{array}{l}12,71 \mathrm{Ac} \\
14,65 \mathrm{Ac} \\
14,14 \mathrm{Ac} \\
13,93 \mathrm{Ac}\end{array}$ & $\begin{array}{l}13,83 \mathrm{Abc} \\
14,81 \mathrm{Abc} \\
14,23 \mathrm{Abc} \\
14,63 \mathrm{Abc}\end{array}$ & $\begin{array}{l}14,70 \mathrm{Ab} \\
15,37 \mathrm{Ab} \\
14,97 \mathrm{Ab} \\
15,51 \mathrm{Ab}\end{array}$ & $\begin{array}{l}15,56 \mathrm{Aa} \\
16,54 \mathrm{Aa} \\
16,43 \mathrm{Aa} \\
16,50 \mathrm{Aa}\end{array}$ & $\begin{array}{l}24,29 A C \\
25,40 A C \\
25,68 A C \\
26,41 A C\end{array}$ & $\begin{array}{l}25,73 \mathrm{Abc} \\
25,69 \mathrm{Abc} \\
26,07 \mathrm{Abc} \\
26,36 \mathrm{Abc}\end{array}$ & $\begin{array}{l}26,24 \mathrm{Aba} \\
26,22 \mathrm{Aba} \\
26,30 \mathrm{Aba} \\
27,01 \mathrm{Aba}\end{array}$ & $\begin{array}{l}26,91 \mathrm{Aa} \\
26,64 \mathrm{Aa} \\
27,29 \mathrm{Aa} \\
27,13 \mathrm{Aa}\end{array}$ \\
\hline
\end{tabular}

Médias seguidas da mesma letra maiúscula, na coluna, e minúscula, na linha, para a mesma variável e solo, não diferem pelo teste de Tukey a $5 \%$.

(2002), que notaram maior influência da densidade do solo na retenção de água em relação à MO.

\section{CONCLUSÕES}

1. A aplicação de $50 \mathrm{Mg} \mathrm{ha}^{-1}$ de biossólido de lodo de esgoto aumentou a agregação do sol o na camada de 0,0-0,1 m, onde foi incorporada.

2. A aplicação de biossólido não influiu sobre a resistência do solo à penetração, tampouco sobre a umidade nos dois solos.

\section{LITE RATURA CITADA}

AGGELIDES, S.M. \& LONDRA, P.A. Effects of compost produced from town wastes and sewage sludge on the physical properties of a loamy and clay soil. Biores. Technol., 71:253-259, 2000.

ALBIACH, R. Estudio de varios índices de actividad biológica del suelo en relación a diferentes aportaciones deenmiendas organicas. Valencia, University of Valencia Publishing Service, 1997. $190 \mathrm{p}$.

ALBIACH, R.; CANET, R.; POMARES, F. \& INGELMO, F. Organic matter components, aggregate stability and biological activity in a horticultural soil fertilized with different rates of two sewage sludges during ten years. Biores. Technol., 77:109-114, 2001.

ANGERS, D.A. Changes in soil aggregation and organic carbon under corn and alfafa. Soil Sci. Soc. Am. J ., 56:1244-1249, 1992.
BEUTLER, A.N.; CENTURION, J .F.; SOUZA, Z.M.; ANDRIOLI, I. \& ROQUE, C.G. Retenção de água em dois tipos de Latossolos sob diferentes usos. R. Bras. Ci. Solo, 26:829834, 2002.

BEUTLER, A.N.; SILVA, M.L.N.; CURI, N.; FERREIRA, M.M.; PEREIRA FILHO, I.A. \& CRUZ, J.C. Agregação de Latossolo Vermelho distrófico típico relacionada com o manejo na região dos cerrados no Estado de Minas Gerais. R. Bras. Ci. Solo, 25:129-136, 2001.

CAMPOS, B.C.; REINERT, D.J .; NICOLODI, R.; RUEDELL, J . \& PETRERE, C. Estabilidade estrutural de um Latossolo Vermelho-Escuro distrófico após sete anos de rotação de culturas e sistemas de manejo de solo. R. Bras. Ci. Solo, 19:121-126, 1995.

EMPRESA BRASILEIRA DE PESQUISA AGROPECUÁRIA EMBRAPA. Manual de métodos de análise de solo. 2.ed. Rio de J aneiro, Ministério da Agricultura, 1997. 212p.

EPSTEIN, E. Effect of sewage sludge on some soil physical properties. Environ. Qual., 4:139-142, 1975.

FERREIRA, M.M.; FERNANDES, B. \& CURI, N. Influência da mineralogia da fração argila nas propriedades físicas de Latossolos da região sudeste do Brasil. R. Bras. Ci. Solo, 23:515-524, 1999.

GRANDY, A.S.; PORTER, G.A. \& ERICH, M.S. Organic amendment and rotation crop effects on the recovery of soil organic matter and aggregation in potato cropping systems. Soil Sci. Soc. Am. J ., 66:1311-1319, 2002.

HADAS, A.; RAWITZ, E.; ETKIN, H. \& MARGOLIN, M. Shortterm variations of soil physical properties as function of the amount and $\mathrm{C} / \mathrm{N}$ ratio of decomposing cotton residues. I. Soil aggregation and aggregate tensilestrength. Soil Till. Res., 32:183-198, 1994. 
J ORGE, J .A.; CAMARGO, O.A. \& VALADARES, J.M.A.S. Condições físicas de um $L$ atossolo Vermel ho-E scuro quatro anos após aplicação de lodo de esgoto e calcário. R. Bras. Ci. Solo, 15:237-240, 1991.

KABATA-PENDIAS, A. \& PENDIAS, H. Trace elements in soils and plants. Flórida, CRC Press, 1992. 365p.

KUMAR, S.; MALLIK, R.S. \& DAHIYA, I.S. Influence of different wastes upon water retention, transmission and contact characteristics of sandy soil. Aust. J . Soil Res., 23:131-136, 1985.

LOGAN, T.J . \& HARRISON, B.J . Physical characteristics of alkaline stabilized sewage sludge (N-Viro soil) and their effects on soil physical properties. J . Environ. Qual., 24:153164, 1995.

MARTINEZ-MENA, M.; WILLIAMS, A.G.; TERNAN, J.L. \& FITZJ OHN, C. Role of antecedent soil water content on aggregates stability in a semi-arid environment. Soil Till. Res., 48:71-80, 1998.

MELO, W.J .; MARQUES, M.O.; SANTIAGO, G.; CHELLI, R.A. \& LEITE, S.A.S. Efeito de doses crescentes de lodo de esgoto sobre frações da matéria orgânica e CTC de um Latossolo cultivado com cana-de-açúcar. R. Bras. Ci. Solo, 18:449-455, 1994.

MELO, W.J .; MARQUES, M.O. \& MELO, V.P. O uso agrícola e as propriedades do solo. In: TSUTIYA, M.T., ed. Biossólido na agricultura. São Paulo, SABESP, 2001. p.289-363.
MELO, V.P. Propriedades químicas e disponibilidade de metais pesados para a cultura do milho em dois Latossolos que receberam a adição de biossólido. J aboticabal, Universidade Estadual Paulista, 2002. 134p. (Tese de Mestrado)

MELO, V.P.; BEUTLER, A.N.; SOUZA, Z.M.; CENTURION, J .F. $\&$ MELO, W.J . Atributos físicos de Latossolos adubados durante cinco anos com biossólido. Pesq. Agropec. Bras., 39:67-72, 2004.

SMITH, C.W.; J OHNSTON, M.A. \& LORENTZ, S. The effect of soil compaction and soil physical properties on the mechanical resistance of South African forestry soils. Geoderma, 78:93-111, 1997.

STOLF, R. Teoria e teste experimental de fórmulas de transformação dos dados de penetrômetro de impacto em resistência do solo. R. Bras. Ci. Solo, 15:229-235, 1991.

STOLF, R.; FERNANDES, J. \& FURLANI NETO, V.L. Recomendação para uso do penetrômetro de impacto, modelo IAA/PIanalsucar - Stolf. São Paulo, MIC/IAA/ PNMCA-Planalsucar, 1983. 8p. (Série penetrômetro de impacto - Boletim, 1)

WEI, Q.F.; LOWERY, B. \& PERTERSON, A.E. Effect of sludge application on physical properties of a silty clay loam soil. J. Environ. Qual., 14:178-180, 1985.

WHALEN, J.K. \& CHANG, C. Macroaggregate characteristics in cultivated soils after 25 annual manure aplications. Soil Sci. Soc. Am. J ., 66:1637-1647, 2002. 